\title{
Language Shift: A Case of Punjabi Language in Sahiwal District,
}

\section{Pakistan.}

\author{
Atiya Rabbani (Corresponding author) \\ MS English Linguistics Scholar \\ English Language Development Centre,Mehran University of Engineering \& Technology \\ Jamshoro,Pakistan \\ E-mail: atiyamehboob@hotmail.com \\ Shoukat Ali Lohat \\ Assistant Professor \\ English Language Development Centre, Mehran University of Engineering \& Technology \\ Jamshoro,Pakistan \\ E-mail: shoukatmuet@gmail.com
}

\begin{abstract}
This study inspects the Punjabi language speakers' attitude which constitutes a threat towards their mother tongue Punjabi in the district of Sahiwal, Punjab where the native users are shifting from their mother tongue to the other language. Questionnaire and observation were used to trace out the trends of shift in this scenario. The results of the study demonstrate that Punjabi speakers are not so much faithful with their native language. This scenario poses a threat to Punjabi language and such speakers' perceptions have brought the major language of the country at a point where new directions and accords are spreading very rapidly in the speech groups and within a few generations this language can die a disastrous death.
\end{abstract}

Key words: language, shift, maintenance, loyalty.

DOI: $10.7176 /$ JLLL/71-06

Publication date: September $30^{\text {th }} 2020$

\section{Punjabi in Pakistan}

According to a list proposed by linguists, there are 72 languages which are spoken in Pakistan and Punjabi is owned by $45 \%$ of its population as their native language. On the other hand, Punjabi is regarded as the 10th mostly widely spoken language in the world by the number of its native speakers. It is one of the "Indo-European Languages". In addition, Punjabi is the provincial language of the province of Punjab.

In spite of the fact that it is widely spoken language of Pakistan, Punjabi is on incline and Punjabi speakers are shifting towards other languages. There is a lack of ownership and an element of shame has been associated with their own language and they tend to shift from their language especially youngers are not interested in preserving and learning their own language and the parents are also opting to drop Punjabi and to teach Urdu as their first language and other dominant languages in various domains of use.

\section{Site}

Sahiwal District is one of the important districts of Central Punjab, Pakistan. It covers approximately $3201 \mathrm{sq} \mathrm{km}$. It is surrounded by districts of Khanewal, Vehari, Pakpattan, Okara and Bahawalnagar. In its north, The River Ravi flows and it comprises of two tehsils namly Chichawatni and Sahiwal. It has many subtowns like Arifwala, Kassowal, Qadirabad and Noorshah. Harrapa which had been one of the famous city of Indus Civilization is also located from $15 \mathrm{~km}$ away from Sahiwal. Sahiwal is mainly an agricultural city which has rich and fertile land. The things which make it more prominent are its cattle, crops, buffaloes, cotton and grain. Due to these things, the local economy of the city depends on agriculture. It has been connected to all other areas of the country via road and railway. At present, a regional airport is also under construction. It has extremely hot climate. It has been upgraded as division since 2008. According to the census of 1998, Punjabi is the major language of the district as $98 \%$ 
population speak Punjabi, $1.4 \%$ population use Urdu and $0.4 \%$ population speak Pashto. Many government educational institutions are working in the district. With these, many campuses of private schools, colleges and universities are functioning in Sahiwal city. Besides Harrapa, another mark of distinction for the city is this that the only Pakistan Nobel Laureate, Dr. Abdus Salam was also born in Sahiwal. He was awarded The Nobel Prize in 1979 for his achievement in Theoretical Physics. The famous Urdu poet, Majeed Amjad also belonged to Sahiwal.

\section{Background of the study}

Language shift also known as language transfer is a major area of sociolinguistics which has been evaluated and observed in different locations and contexts throughout the world. It is not a new thing at all. One of the earliest research on language shift was conducted by a famous linguist Joshu Fishman who used U.S. Census Bureau data. (Veltman, 1983)

According to Jaspaert \& Kroon (1989), language shift process can be defined as the gradual disappearance of a language in a specific community where once it was being used by the speakers of that community. Weinreich $(1953 ; 68)$ advocates that shift in a language occurs when speakers of a language move away from constant use of their native language to that of other language as multilingualism and bilingualism are the phenomenon found in every part of the world. Hoffman (1991: 186) states that when a speech group does not tend to maintain its language and slowly takes up another language then the shift in a language occurs.

While in the process of language shift, it is a speaker's attitude and perception that plays an important role in shifting a language as Gardner, Holmes and Harlow $(1985,1991)$ propose that attitude is one of the major element that has a prominent impact on language shift. Baker (1992) pointed to attitude as conceptual element that is used to direct the human behavior. So, language shift shows our internal thoughts, feelings and behavior in various contexts.

In the case of Punjabi language, Ejaz in his article; "The status of Punjabi in west Punjab: A historical perspective" criticizes that it is shameful for the speakers that they want to rule over the others but when they are asked to speak their own mother tongue, they do not dare to do so. Punjabis keep themselves away from their mother tongue and do not let it spoil their so-called elite status and image.

Zaidi (1990) states, "Pakistani Punjabis' negative attitude towards their language can be demonstrated by the fact that there is not a single newspaper or magazine published in Punjabi. The latest venture was a daily newspaper, Sajjan ("Friend"), edited and published by Hussain Naqi, an Urdu-speaking Indian emigrant. It only lasted a few months".

\section{Research problem:}

Punjabi has become a tolerated language for its speakers and is losing its status In Punjab. Younger speakers have a negative attitude towards it and older members are also not interested in its preservation and such attitudes are demolishing the status of the major language of the country and it may result in language death one day. In this regard, speakers' perceptions and attitudes play a vital role in language shifting. This study attempts to trace out the Punjabi speakers' perceptions about their native language to determine the factors involving in this process of language shift. It divulges the reasons behind this scenario.

\section{Objectives:}

The major objectives of the study are;

$>$ To trace out the perceptions of Punjabi speakers about the status of Punjabi in Sahiwal District, Pakistan.

$>$ To investigate the reasons and factors behind the shift in Punjabi Language in Sahiwal District, Pakistan.

\section{Research Questions:}

To get a comprehensive and in-depth understanding of the speakers' perceptions, the following questions have been designed.

$>$ What are the Punjabi speakers' general perceptions about their language in Sahiwal District?

$>$ What are the reasons of shift in Punjabi language? 


\section{Literature Review}

Numerous studies have been conducted by the researchers in international context. Most of these studies explored the domains of language shift, factors involving in this process and the speakers' perceptions about their native languages and trends towards the shifting of language. Different reasons have been identified by different researchers.

While identifying the reasons of language shift, Appel \& Muysken (1987) are of the opinion that language shift occurs because the speakers of minority tongue adopt the majority language as they expect to get better chances for uplifting of the status, social mobility and economic success by speaking that language. Dorian (1982) suggests that the replacement of one language with another occurs when two concerned languages enjoy different level of prestige and official support. According to Richard (1992), the reason behind language shift is the migration to another country. It is further encouraged by the official government policy, media of instruction, employment opportunities and wider communication. Further, Romaine (1995) highlights that the basic external factors responsible for language shift are numerical strength of the group, social class, religious and educational setting, ways of living, bond with the homeland, harmony between the different social groups and patterns of language use. Saville-Troike (1989) points out that marriage and blood relations may also play their role in language shift. When the women are educated and participate in trade or other outer activities, they tend to shift the language while the uneducated women stay at home and remain monolingual.

Babane, M. T., \& Chauke, M. T. (2016) conducted personal interviews, surveys and observations of 30 Xitsonga in the city of Polokwane aimed to find out the factors involved in language shift. The study revealed that South Africa having eleven major languages is not providing the same status to its all languages. Some are being considered as having lower status even by their own speakers. The study pointed out that in regard to prestige, rights, entitlement and power, English and Northern Sotho are more superior as compared to the other languages spoken in South Africa and this is the main factor due to which Xitsonga speakers are shifting from their language.

A Malaysian research was conducted by Babu, K. D. (2016) on shifting in language among the Telegu Community in Klang Valley to find out the reasons behind the language shift, quantitative and qualitative approaches were adopted. A questionnaire was administered on 100 Telegu participants residing in Klang Valley and from the same area 10 participants were interviewed. The study demonstrated that Telegu community is shifting towards English because English is being considered much important for educational, academic and professional advancement while they have a great regard for their tongue and culture.

Nyota, S. (2015) evaluated the ethnolinguistic vitality of the Tonga community of Mkoka in Gokwe South, Zimbabwe while focusing on Tonga language and their shift to the Shona language. A combined approach towards methods was applied. Interviews, questionnaire and observations were made. 15 participants from upper primary level and 5 from secondary level from schools reported through a questionnaire. Some elderly and young Tonga persons who were working as cattle herders and maids for their Shona masters and 2 lower class students were interviewed. The researcher whose home was in Mkoka also made observations of the participants. The results showed that Tonga used their first language in their informal domains like home, family, friends and neighbours. But as they move to their social activities and social environment, they shift to Shona that is enjoying a high status in the areas as being the most dominant language economically. So, this study also led to the conclusion that people mostly shift to a language which is dominant in the domain of economy.

Dweik, B. S., \& Nofal, M. Y. (2013) carried out a study on Indians descendants living in Yemen. The study aimed at finding out their attitudes towards their native Indian languages and the factors played their role in losing their native language. 86 participants responded to a six-sectioned questionnaire. The study showed that some of them still maintain their ethnic languages due to linguistic, social, political and attitudinal factors.

Two villages named as Lampeni and Bawalipu, Wotu Disericr, East Luwu REGENCY were selected by Masrudin, M. (2013) to find out the factors responsible for the process of shifting in Wotunese language. The method of field survey comprising questionnaire and direct observations was used. The sample population was of 400 males and females living in those villages for about ten years. Their ages were upto 10 to 50 years. The study demonstrated that the factors involved in influencing Wotunese language were; age, mobility, bilingualism and language attitude. The researchers also suggested government and wotunese to take serious steps to save the language from death.

R.Zaman (2014) conducted a study aiming at finding the domains of the language shift and its determinants in the widely spoken language in Pakistan; Punjabi. At initial stages, discussions and preliminary interviews were conducted. After it, a questionnaire as research instrument was administered while dividing the participants into teenagers, 20-30 yrs old, 31-55 yrs old and 56-above. The study concluded that owing to the lack of ownership 
and regard for Punjabi language, the Punjabi speakers have a tendency to move from their own native language. The element of distress associated with the use of their own language was also traced out. The major domains of shift were home, interaction with friends, selecting TV channels, etc. parents and young generation wanted to learn English due to its association with the element of power.

Gillani, M., \& Mahmood, M. A. (2014) investigated different attitudes of the speakers in Punjab towards Punjabi language especially the younger speakers who had stopped speaking this language. A survey research was carried on and sample comprised of 60 young graduates and post- graduates from the Government College Faisalabad and their parents. The study concluded that Punjabi speakers are not interested in learning and preservation of Punjabi. Punjabis are not devoted to their own language. Because of such attitude of the speakers, the Punjabi language is losing its ranking in Punjab and it is being treated as a tolerated language that can result in language death one day.

Nazir, B., Aftab, U., \& Saeed, A. (2013) examined the causes, attitudes and effects of Punjabi language shift in Sargodha, Pakistan. Triangulation (Questionnaires from $n=80$ and In-depth interviews from $n=3$ ) was applied to collect data. Sample size comprised 100 participants. The study highlighted that speakers of Punjabi language were not allegiant to their own language and are inclined towards Urdu. The reasons behind this scenario are lack of prestige, lack of power, linguistic indignity, etc.

S.Nawaz, A.Umer, F.Anjum, M.Ramzan (2012) attempted to analyze the factors that are responsible for banishing the status of Punjabi by an adoption of English language. The data was collected through a self-designed questionnaire with a sample population of 100 participants. The historical, cultural, social, economic and psychological factors are found involved though, at varying degree, in this ever-increasing shift from Punjabi to English. As we humans are the social animals and our material and physical needs are our primary concern so Punjabi speakers are shifting to English. Much economic considerations are attached to English language so it is fulfilling our economic needs to a great extent.

\section{Methodology}

To achieve the objectives of the research, the both types of data is collected. In quantitative, the questionnaire is designed and administered carrying closed-ended questions. The qualitative data is collected in the form of semistructured interviews to drive the results out. The software used is Spread sheet.

The following diagram can help us more to explain the sampling method.

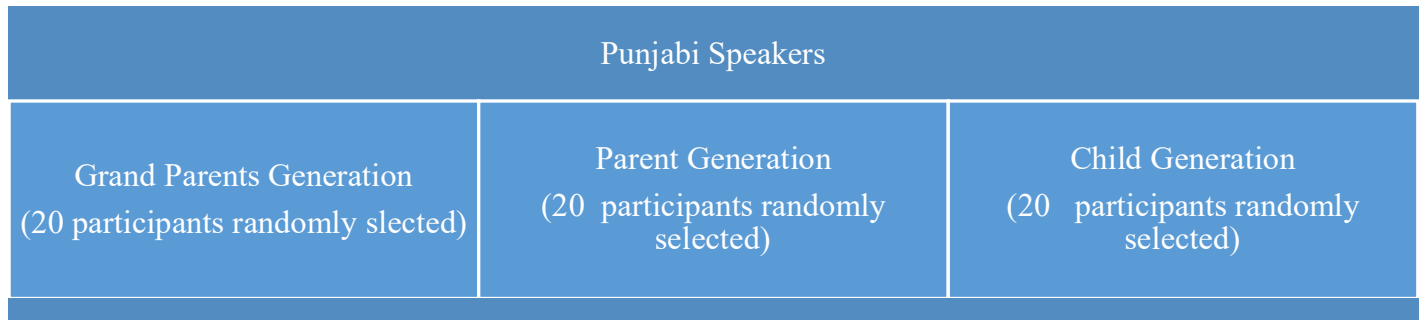

\section{Data Analysis, Interpretations and Discussion}

9.1 Semi- Structured Interviews

For the conduction of semi structured interviews, one speaker from each group was selected and some questions were asked about their attitude towards their native language. The first speaker was a male from the first generation and he was 62 years old. He was living in the urban area of the district of Sahiwal. The second participant was a housewife belonging to the parent generation and she was 35 years old. The third speaker was a young boy studying at a prominent university campus in Sahiwal. He was 21 years old.

\subsubsection{Speaker 01}

The first speaker was of the opinion that Punjabi language should be preserved and the young generation should learn it. But for the end, the government should take measures steps to promote the language. The youngsters should be encouraged to learn Punjabi minimum upto primary level. The shameful attitude with this language should be eliminated. Language can be promoted and can enjoy a good status it is allowed to enjoy a special status in somehow the domains of power in the country. 


\subsubsection{Speaker 02}

The second speaker who was a housewife was of the opinion that Urdu and English should be taught in the schools because it can ensure a better future for the children. The learning of Punjabi for the youngsters is totally the wastage of time and no advantage can be gained. The Punjabi can be used only in the domain of house where elder members are used of speaking Urdu or English. The parents should encourage the kids to learn the modern language and any governmental attempt will be in vain.

\subsubsection{Third Speaker}

The third speaker was a young boy who was studying at a university. According to him, with the fast growing world, Punjabi language has no use at all. The teaching of regional languages should be stopped and the modern languages should be taught so that the learners could be able to raise their status and better opportunities for the employment could be provided. He finds it disgraceful to use Punjabi in his formal setting especially at his academic place.

\subsection{Questionnaire}

A questionnaire is administered carrying closed-ended questions. To get the comprehension of the responses, the results can be discussed in the form of the following charts taking the questions step by step.

What Language is used by you at home?

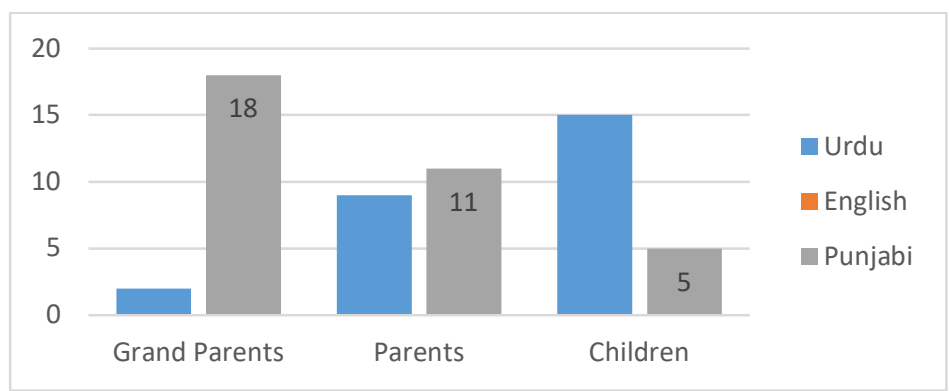

The answer demonstrates the fact that grand generation tend to use their mother tongue for communication with most of the family members. This fact highlights the loyalty of the elder members with their language. The parent generation uses Urdu for this purpose and the children use Urdu but the use of Punjabi is being traced on an incline. While the most of the parents from the second generation continue using Punjabi with the grand-parents. The children are quite unaware of the prestige associated with Punjabi. The trend shows a clear shift from Punjabi language to the other languages that is happening at a great speed.

What language do you use outside the home?

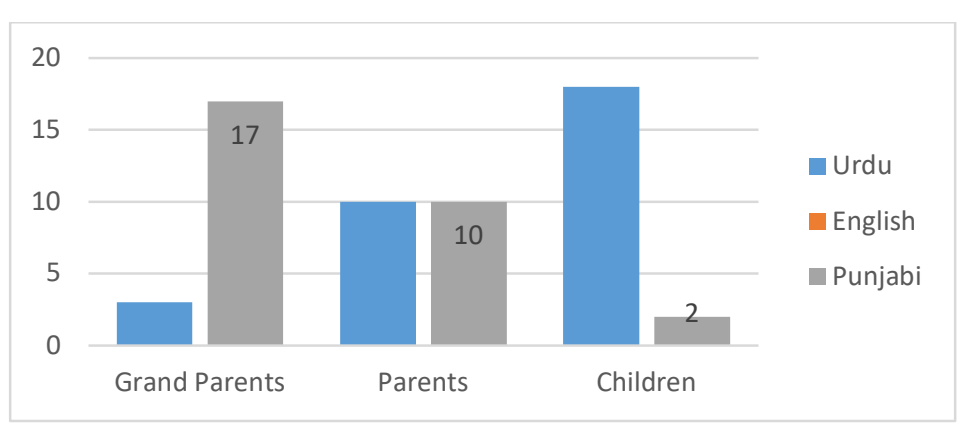

The perceptions regarding the use of Punjabi outside of the home was assessed with the help of this question. The grand parents because of being the native and fluent speaker of Punjabi tend to use Punjabi outside of the home. While doing shopping, interacting with the Punjabi speaking friends, etc. They prefer to use their native language and are quite comfortable with it. On the other hand, $50 \%$ of the parents from the second generation try to maintain the language as per the convenience of the situation. With the strangers, mostly they try to communicate in the language convenient for all participants. In informal situation. They try to speak the language of the next 
participant. Contrary to it, the young generation try to avoid using the language of the elders. They feel shameful while using Punjabi in front of their friends or class fellows. Outside the home, the children try to maintain the language of the power.

\section{Which language do you use to interact with your kids?}

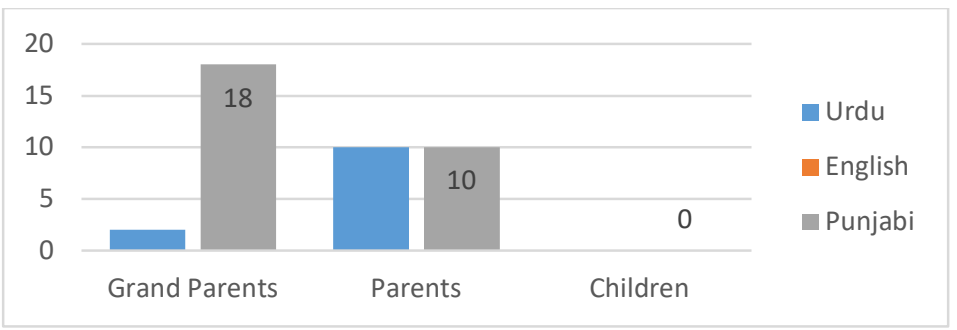

In the light of the responses collected back after this question, it can be traced very easily that $90 \%$ of the grandparents use Punjabi to interact with their kids. On the other hand, 50\% of the parents from the second generation are in favour of using Punjabi. Unfortunately, such attitude creates an alarm for the widely spoken language of the country.

\section{Is Punjabi used by you to communicate with your non speaking Punjabi friends?}

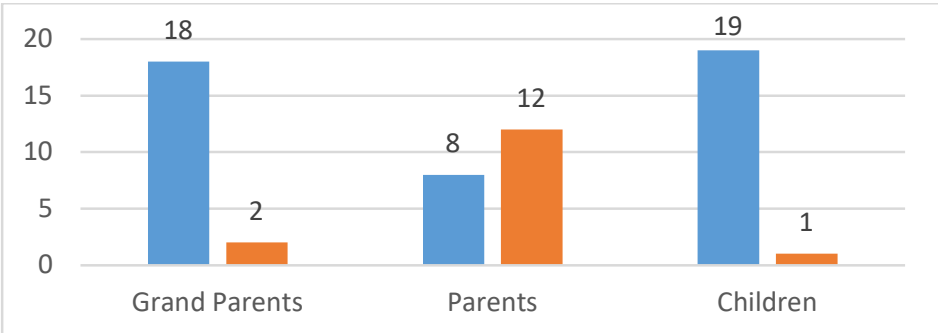

$90 \%$ of the grand-parents continue using Punjabi with their non-Punjabi speaking friends. The participants from the second group of parents have adopted Urdu along with Punjabi. It is quite alarming that the children are shifting to other language in place of their mother tongue. They avoid using Punjabi in front their non-Punjabi speaking friends. At schools and at other places of interaction, they do not prefer using Punjabi over the other language. Such attitude can bring the major language of the country at the edge of danger and this language can die a disastrous death.

\section{Would you like to transmit Punjabi to the next generation?}

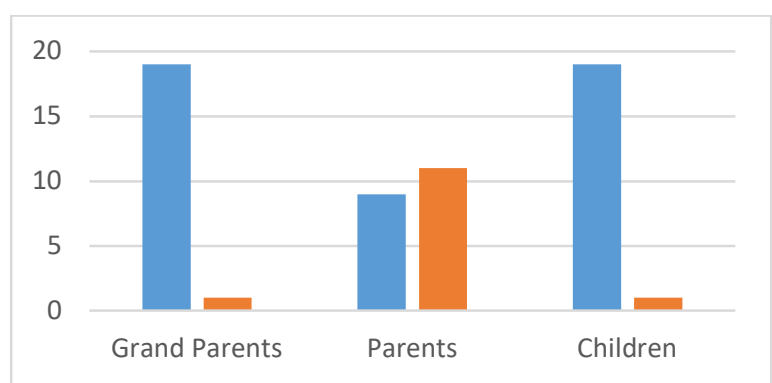

The last and the most important question was formed to assess the perceptions of the Punjabi speakers about the transmission of their mother tongue to the next generation. In accordance with the previous responses, the grand parents are too much with Punjabi. Here, again they want to transmit it to the next generation. In the second group of the participants, the parents are interested in the maintenance of Punjabi in the next generation but unfortunately, 
the latest developments stop them from doing so. After of the remedial steps, they have a hope for the survival of the language. The last group did not responded positively. In case of having kids, they are not interested in its transmission. $2 \%$ participants have a wish to do so but such low prestige with the mother tongue shows the lack of ownership and loyalty.

\section{Findings}

The all participants were divided into three different age groups based on three generation so the main variable was age. The main trends of shift were observed among the young speakers as compared to the elder speakers. They young speakers prefer Urdu and English over their native language. Even, in informal settings the youngsters talk in Urdu as they find Punjabi less prestigious. It was traced out that the Punjabi speakers have linked a feeling of shame with the use of Punjabi language and they avoid using it in front of their colleagues and friends. The young speakers are not of the opinion that Punjabi should be promoted in any domain of life as it minimize the chances of getting good employment in future. Such attitude and perceptions shows a clear threat to Punjabi language in Pakistan.

On the other hand, the elder generation possess a soft feeling towards their language and try to maintain it in many domains of use in their everyday life. But, due to increasing demand for the advanced languages and technology, they want their next generation to learn Punjabi language at least in primary schools. They want such steps to ensure the transmission of one language from-one generation to the next generation.

This study exhibits a clear trend of shift in the use of Punjabi language. But, it also provides a ray of hope. The elder speakers are loyal with their language and demand some steps for the transmission of language. It is found that usually the young children are not aware of the rich culture associated with their mother tongue. The efforts from parents' side can make them realize the importance of the mother tongue and the smooth transmission can be ensured.

\section{Conclusion}

Punjabi language which is the mostly spoken language in Pakistan is losing its status and speakers day by day due to the prevalence of other powerful languages enjoying power and support at institutional level. Due to which, the Punjabi speakers are diverting their loyalties. Therefore, it is necessary to start different remedial projects for the survival and development of the major language of the country. Moreover, the young generations should be encouraged to learn Punjabi as their mother tongue so that this language can be sustained over a long time.

\section{References}

Babane, M. T., \& Chauke, M. T. (2016). Xitsonga in language shift: A sociolinguistic approach. Journal of Social Sciences, 47(1), 49-57.

Babu, K. D. (2016). Language shift and maintenance among the Telugu community in the Klang Valley (Doctoral dissertation, Jabatan Bahasa-bahasa Asia dan Eropah, Fakulti Bahasa dan Linguistik, Universiti Malaya).

Baker, C. (1992). Attitudes and language (Vol. 83). Multilingual Matters.

Dorian, N. C. (1982). Defining the speech community to include its working margins. Sociolinguistic variation in speech communities, 25-33.

Dweik, B. S., \& Nofal, M. Y. (2013). Language maintenance among the Indians of Yemen:

Gardner, M. P. (1985). Does attitude toward the ad affect brand attitude under a brand evaluation set?. Journal of Marketing Research, 192-198.

Gillani, M., \& Mahmood, M. A. (2014). Punjabi: A tolerated language young generation's attitude. Research on Humanities and Social Science Journal, 4(5), 129-137.

https://globaljournals.org/GJHSS Volume12/10-Language-Shift-An-Analysis.pdfof Pakistan. Acta Linguistica Asiatica, 3(2), 41-60

https://issuu.com/learnenglishin30days/docs/language shift in punjabi language

Jaspaert, K., \& Kroon, S. (1989). Social determinants of language loss. ITL-International Journal of Applied Linguistics, 83(1), 75-98. 
Nazir, B., Aftab, U., \& Saeed, A. (2013). Language shift-The case of Punjabi in Sargodha region S.Nawaz, A.Umer, F.Anjum, M.Ramzan (2012). Language shift : An Analysis of Factors involved in Language Shift

Nyota, S. (2015). Language shift among the Tonga of Mkoka? Assessing ethnolinguistic vitality in Gokwe South. South African Journal of African Languages, 35(2), 215-224.

R.Zaman (2014). Language Shift in Punjabi Language

Romaine, S. (1995). The grammaticalization of irrealis in Tok Pisin. Modality in grammar and discourse, $32,389$.

Saville-Troike, M. (1989). Attitudes toward communicative performance. The Ethnography of Communication. Oxford: Brasil Blackwell.

Tuwakham, M. (2005). Language vitality and language attitude among the young people in Lamphun province: A sociolinguistic study. Unpublished MA thesis), Chiang Mai, Thailand: Payap University.

Veltman, C. J. (1983). Language shift in the United States (No. 34). Walter de Gruyter.

Weinreich, U. (1986). Is Structural Dialectology Possible?. In Dialect and Language Variation (pp. 20-34). Academic Press.

Zaidi, A. (2010). A Postcolonial sociolinguistics of Punjabi in Pakistan. 